\title{
A Computational fluid dynamics (CFD) comparison of 3-Lump and 4-Lump kinetic models for predicting gasoline, light gases and coke yield in fluid catalytic cracking (FCC) riser
}

\author{
Muhammad AhSAN ${ }^{\mathrm{a}}$ \\ School of Chemical \& Materials Engineering, National University of Sciences \& Technology Islamabad 44000, Pakistan
}

Received 18 July 2014, Accepted 11 December 2014

\begin{abstract}
In this study a comparison of 3-lump and 4-lump kinetic models predicting the yield of gasoline, light gases and coke in FCC riser has been done. Commercial CFD software with K-epsilon turbulence model is used to investigate the reactions occurrence between fluid and solids in a fluidized bed. An important feature of this model is that its kinetics includes partial differential equations. This provides accurate predictions of product yields in the FCC riser. In this simulation different process variables such as temperature and feed rate are changed to investigate the effect on product yields. Time accurate transient problem is solved with the prediction of yield profiles of gas oil, gasoline, light gas and coke. The output curves demonstrate the breaking of heavy hydrocarbon in the presence of catalyst. An approach proposed in this study shows good agreement with the experimental and numerical data available in literature.
\end{abstract}

Key words: FCC riser / computational fluid dynamics (CFD) / 3-lump kinetic model / 4-lump kinetic model / hydrodynamics / k-epsilon turbulence model

\section{Introduction}

The Fluid catalytic cracking (FCC) is one of the key processes in the oil refining industry. High molecular weight hydrocarbons are cracked catalytically to more valuable products of low molecular weight. In FCC riser, dense catalyst bed is pushed upward by lift steam from the base of the riser to feed injection point. The high molecular weight feed comes in contact with the hot catalyst and evaporates rapidly. The feed is cracked into lighter hydrocarbons (gasoline and light gases). The hot catalyst provides the heat for this endothermic cracking reaction. The activity of catalyst is reduced by the coke deposited on the catalyst during the reaction. The similar components of FCC process are grouped as "lumps". The catalytic cracking of hydrocarbons is very complex due to many reactions and chemical species involved. Therefore, the reaction kinetics has been investigated by making lumps of numbers of chemical compounds. Several catalytic cracking reaction kinetic models for the FCC process have been proposed by different researchers. Weekman and Nace [1] developed a simple kinetic scheme, based on the theory of Wei and Prater [2], for the kinetic modeling of cracking reactions occurring in the riser reac-

${ }^{a}$ Corresponding author: ahsan@scme.nust.edu.pk tor. This work can be considered as pioneer in developing the simple kinetic mechanism for FCC modeling purposes. Authors divided the charge stock and products into three components, namely, the original feedstock, the gasoline and the remaining C4's (dry gas and coke), and hence simplified the reaction scheme. The model predicted the conversion of gas oil (the feedstock) and gasoline yield in isothermal condition in fixed, moving, and fluid bed reactors. The kinetic parameters of the model were evaluated using the experimental data. Since the gas oil and gasoline cracking rates have different activation energies, an optimum reactor temperature was also determined for the system. Lee et al. [3], Dave et al. [4] and Gianetto et al. [5] proposed the 4-lump kinetic model by dividing light gases plus coke lump into two separate lumps of light gases and coke.

This study is novel because 3-lump and 4-lump kinetic models are compared numerically first time by the using computational fluid dynamics (CFD) with the finite volume method (FVM). Some details of the FVM used by the solver are carefully discussed when implementing terms in the governing equation and boundary conditions (BC) [6-9]. The basic difference between 3-lump and 4-lump kinetic models is the availability of additional lump in 4-lump kinetic model. In 3-lump kinetic model, a single lump is used to represent the mass fraction and 


\section{Nomenclature}

\begin{tabular}{|c|c|}
\hline$C_{\mathrm{D}}$ & Drag coefficient \\
\hline$C_{\mu}$ & Turbulence constant \\
\hline$d_{\mathrm{s}}$ & Diameter of solid particles, $\mathrm{m}$ \\
\hline$e_{\mathrm{s}}$ & Particle collisions coefficient \\
\hline$g$ & Gravitational acceleration, $\mathrm{m} \cdot \mathrm{s}^{-2}$ \\
\hline$g_{\mathrm{o}}$ & Radial distribution function \\
\hline$H_{i}$ & Specific enthalpy of $i$ th phase, ${\mathrm{J} . \mathrm{kg}^{-1}}^{-1}$ \\
\hline$k_{\Theta \mathrm{s}}$ & Diffusion coefficient, $\mathrm{kg} \cdot \mathrm{m}^{-1} \cdot \mathrm{s}^{-1}$ \\
\hline$k_{i}$ & Turbulent kinetic energy, J.kg ${ }^{-1}$ \\
\hline$P$ & Static pressure, N.m ${ }^{-1}$ \\
\hline$P_{\mathrm{s}}$ & Solid pressure, N.m ${ }^{-1}$ \\
\hline$q_{i}$ & Heat flux, W.m ${ }^{-2}$ \\
\hline$R e_{\mathrm{s}}$ & Relative Reynolds number \\
\hline$T_{s}$ & Solid stress tensor, $\mathrm{Pa}$ \\
\hline$U_{i}$ & Velocity of $i$ th phase, m.s ${ }^{-1}$ \\
\hline$\alpha$ & Turbulent kinetic energy dissipation rate, $\mathrm{m}^{2} \cdot \mathrm{s}^{-3}$ \\
\hline$\beta$ & Solid gas exchange coefficient, $\mathrm{kg} \cdot \mathrm{m}^{-3} \cdot \mathrm{s}^{-1}$ \\
\hline$\rho_{i}$ & Density of $i$ th phase, kg. ${ }^{-3}$ \\
\hline$\varepsilon_{i}$ & Volume fraction of $i$ th phase \\
\hline$\epsilon_{i}$ & Turbulent dissipation rate, $\mathrm{m}^{2} \cdot \mathrm{s}^{-3}$ \\
\hline$\tau_{i}$ & Shear stress tensor of $i$ th phase, N.m ${ }^{-2}$ \\
\hline$\gamma_{\mathrm{s}}$ & Collisional dissipation of energy, $\mathrm{kg} \cdot \mathrm{m}^{-1} \cdot \mathrm{s}^{-3}$ \\
\hline$\Theta_{\mathrm{s}}$ & Granular temperature, $\mathrm{m}^{2} \cdot \mathrm{s}^{-1}$ \\
\hline$\mu_{\mathrm{b}}$ & Solid bulk viscosity, $\mathrm{kg} \cdot \mathrm{m}^{-1} \cdot \mathrm{s}^{-1}$ \\
\hline$\mu_{i}$ & Viscosity of $i$ th phase, $\mathrm{kg} \cdot \mathrm{m}^{-1} \cdot \mathrm{s}^{-1}$ \\
\hline$\mu_{\mathrm{s}, \mathrm{dil}}$ & Solid phase dilute viscosity, $\mathrm{kg} \cdot \mathrm{m}^{-1} \cdot \mathrm{s}^{-1}$ \\
\hline$\mu_{\mathrm{t}}$ & Turbulent viscosity kg.m $\mathrm{m}^{-1} \cdot \mathrm{s}^{-1}$ \\
\hline
\end{tabular}

reaction kinetics of both light gases and coke. While in 4-limp kinetic model separate lumps are used for light gases and coke. Due to the availability of extra lump, numerical model can predict the result more accurately. In this work, a heavy density catalyst has been used to develop a two dimensional hydrodynamics and reaction kinetics model of FCC riser reactor. Heavy density catalyst provides catalytic activity sites, as compared to zeolite there are larger pores that provide entry for larger molecules. This makes the cracking of larger molecules of higher boiling point possible. This catalyst increases the conversion of light gases to gasoline significantly. The FVM solver FLUENT 6.3 is used to simulate FCC riser reactors. The model studies two-phase flow of catalyst and vapor. It described the temperature profiles, mass fraction profiles and the yield of gasoline product in the FCC riser. The results obtained separately from 3-lump and 4-lump kinetic models are compared in this article.

\section{Mathematical modeling}

A granular Eulerian-Eulerian multiphase model is used to simulate the hydrodynamics of the multiple phases. In Fluent 6.3 CFD code, finite volume method is used to discretize the conservation equations.

\subsection{Conservation equations}

The continuity equation of phase $i$ ( $i=$ gas, solid) is given by:

$$
\frac{\partial}{\partial t}\left(\rho_{i} \varepsilon_{i}\right)+\nabla \cdot\left(\rho_{i} \varepsilon_{i} U_{i}\right)=0
$$

with definition: $\varepsilon_{\mathrm{g}}+\varepsilon_{\mathrm{s}}=1$.

The conservation of momentum of phase $i$ ( $i=$ gas, solid, $k \neq i$ ) can be written as

$$
\begin{aligned}
\frac{\partial}{\partial t}\left(\rho_{i} \varepsilon_{i} U_{i}\right)+\nabla \cdot\left(\rho_{i} \varepsilon_{i} U_{i} U_{i}\right)=-\varepsilon_{i} \nabla P & +\nabla \tau_{i}+\rho_{i} \varepsilon_{i} g \\
& -\beta\left(U_{i}-U_{k}\right)
\end{aligned}
$$

The conservation of energy for phase $i$ yields

$$
\frac{\partial}{\partial t}\left(\varepsilon_{i} \rho_{i} H_{i}\right)+\nabla \cdot\left(\varepsilon_{i} \rho_{i} U_{i} H_{i}\right)=-\varepsilon_{i} \frac{\partial P_{i}}{\partial t}+\tau_{i}: \nabla U_{i}-\nabla q+S_{i}
$$

\subsection{Interphase exchange coefficients}

From the Syamlal-O'Brian model for the drag force formulation [10]

$$
\beta=\frac{3}{4} C_{\mathrm{D}} \frac{\varepsilon_{\mathrm{s}} \varepsilon_{\mathrm{g}}}{2} \frac{\rho_{\mathrm{g}}}{d_{\mathrm{s}}}\left(\frac{R e_{\mathrm{s}}}{v_{r, \mathrm{~s}}}\right)\left|U_{\mathrm{s}}-U_{\mathrm{g}}\right|
$$

The drag coefficient, $C_{\mathrm{D}}$ is given by [11]

$$
\begin{aligned}
C_{\mathrm{D}} & =\left(0.63+\frac{4.8}{\sqrt{R e_{\mathrm{s}} / v_{r, \mathrm{~s}}}}\right)^{2} \\
R e_{\mathrm{s}} & =\frac{\rho_{\mathrm{g}} d_{\mathrm{s}}\left|U_{\mathrm{s}}-U_{\mathrm{g}}\right|}{\mu_{g}}
\end{aligned}
$$

where $\nu_{\mathrm{r}, \mathrm{s}}$ is the terminal velocity correlation for the solid phase [12]:

$$
\begin{aligned}
& v_{\mathrm{r}, \mathrm{s}}=0.5 \sqrt{\left(0.06 R e_{\mathrm{s}}\right)^{2}+0.12 R e_{\mathrm{s}}(2 B-A)+A^{2}} \\
& +0.5 A-0.03 R e_{\mathrm{s}}
\end{aligned}
$$

where:

$$
\begin{aligned}
& A=\varepsilon_{\mathrm{g}}^{4.14} \\
& B=0.8 \varepsilon_{\mathrm{g}}^{1.28} \text { for } \quad \varepsilon_{\mathrm{g}} \leq 0.85 \\
& B=0.8 \varepsilon_{\mathrm{g}}^{2.65} \text { for } \quad \varepsilon_{\mathrm{g}}>0.85
\end{aligned}
$$

\subsection{Solids pressure}

The solids phase pressure $\left(P_{s}\right)$ consists of kinetic term and the particle collisions term. It is calculated from the equation of state which is the same as the Van der Walls equation of state for gases [13]

$$
\begin{aligned}
P_{s}=\left(1+2\left(1+e_{\mathrm{s}}\right) \varepsilon_{\mathrm{s}} g_{\mathrm{o}}\right) \varepsilon_{\mathrm{s}} \rho_{\mathrm{s}} \Theta_{\mathrm{s}} & =\rho_{\mathrm{s}} \varepsilon_{\mathrm{s}} \Theta_{\mathrm{s}} \\
& +2 g_{\mathrm{o}} \rho_{\mathrm{s}} \varepsilon_{\mathrm{s}}^{2} \Theta_{\mathrm{s}}\left(1+e_{\mathrm{s}}\right)
\end{aligned}
$$


where $\Theta_{\mathrm{s}}$ is the granular temperature, $e_{\mathrm{s}}$ is the coefficient of restitution for particle collisions. $g_{\mathrm{o}}$, the radial distribution function [14] is given by:

$$
g_{\mathrm{o}}=\left[1-\left(\frac{\varepsilon_{s}}{\varepsilon_{s, \max }}\right)^{\frac{1}{3}}\right]^{-1}
$$

The value of maximum solid packing, $\varepsilon_{\mathrm{s}, \max }$ for this simulation is 0.53 .

\subsection{Solid shear stress}

The solids stress tensor contains bulk and shear viscosities. The solid phase bulk viscosity can be expressed as [15]:

$$
\mu_{b}=\frac{4}{3} \varepsilon_{\mathrm{s}} \rho_{\mathrm{s}} g_{\mathrm{s}}\left(1+e_{\mathrm{s}}\right)\left(\frac{\Theta_{\mathrm{s}}}{\pi}\right)^{1 / 2}
$$

The solids phase shear viscosity is given by [16]

$$
\begin{aligned}
\mu_{\mathrm{s}}=\frac{2 \mu_{\mathrm{s}, \mathrm{dill}}}{(1+e) g_{\mathrm{o}}}[1+ & \left.\frac{4}{5}\left(1+e_{\mathrm{s}}\right) g_{\mathrm{o}} \varepsilon_{\mathrm{s}}\right]^{2} \\
& +\frac{4}{5} \varepsilon_{\mathrm{s}} \rho_{s} d_{\mathrm{s}}\left(1+e_{\mathrm{s}}\right)\left(\frac{\Theta_{s}}{\pi}\right)^{1 / 2}
\end{aligned}
$$

The solid phase dilute viscosity is:

$$
\begin{aligned}
\mu_{\mathrm{s}, \mathrm{dil}} & =\frac{5}{16} \rho_{\mathrm{s}} \varepsilon_{s} l_{\mathrm{s}} \sqrt{2 \pi \Theta_{\mathrm{s}}} \\
l_{s} & =\frac{\sqrt{2}}{12} \frac{d_{\mathrm{s}}}{\varepsilon_{\mathrm{s}}}
\end{aligned}
$$

\subsection{Granular temperature}

The granular temperature $\Theta_{\mathrm{s}}$ is calculated by solving the turbulent kinetic equation for solid phase:

$$
\frac{3}{2} \frac{\partial}{\partial t}\left(\rho_{\mathrm{s}} \varepsilon_{\mathrm{s}} \Theta_{\mathrm{s}}\right)+\nabla \cdot\left(\rho_{\mathrm{s}} \varepsilon_{\mathrm{s}} \mathrm{U}_{\mathrm{s}} \Theta_{\mathrm{s}}\right)=T_{\mathrm{s}}: \nabla \cdot\left(k_{\Theta \mathrm{s}} \nabla \Theta_{\mathrm{s}}\right)-\gamma_{\mathrm{s}}
$$

The diffusion coefficient for granular energy, $k_{\Theta \mathrm{s}}$ is represented by

$$
\begin{aligned}
k_{\Theta \mathrm{s}}=\frac{2 k \Theta_{\mathrm{s}, \text { dill }}}{\left(1+e_{\mathrm{s}}\right) g_{\mathrm{o}}}(1 & \left.+\frac{6}{5}\left(1+e_{\mathrm{s}}\right) g_{\mathrm{o}} \varepsilon_{\mathrm{s}}\right)^{2} \\
& +2 \varepsilon_{\mathrm{s}}^{2} \rho_{\mathrm{s}} d_{\mathrm{s}} g_{\mathrm{o}}\left(1+e_{\mathrm{s}}\right)\left(\frac{\Theta_{\mathrm{s}}}{\pi}\right)^{1 / 2}
\end{aligned}
$$

where:

$$
k_{\Theta_{\mathrm{s}, \mathrm{dill}}}=\frac{75}{64} \rho_{\mathrm{s}} \varepsilon_{\mathrm{s}} l_{\mathrm{s}} \sqrt{2 \pi \Theta_{\mathrm{s}}}
$$

The collisional energy dissipation, $\gamma_{\mathrm{s}}$ is given by:

$$
\gamma_{\mathrm{s}}=3\left(1+e_{\mathrm{s}}^{2}\right) \varepsilon_{\mathrm{s}}^{2} \rho_{\mathrm{s}} g_{O} \Theta_{\mathrm{s}}\left[\frac{4}{d_{\mathrm{s}}}\left(\frac{\Theta_{\mathrm{s}}}{\pi}\right)^{1 / 2-\nabla U_{\mathrm{s}}}\right]
$$

\section{6 k-epsilon turbulence model}

Generally, the FCC riser reactor is under turbulent flow conditions. Therefore, it is important to use an appropriate turbulence model to describe the effect of turbulent fluctuations of velocities and scalar variables for the basic conservation equations. A $k-\varepsilon$ model was used to describe the turbulent motions in both phases. In the $k-\varepsilon$ model, the turbulent viscosity is defined as:

$$
\mu_{t, i}^{(t)}=\rho_{i} \varepsilon_{i} C_{\mu} \frac{k_{i}^{2}}{\epsilon_{i}}
$$

The turbulence kinetic energy, $k$, and its rate of dissipation, $\varepsilon$, can be calculated from the following transport equations:

$$
\begin{aligned}
\frac{\partial}{\partial t}\left(\rho_{i} \varepsilon_{i} k_{i}\right)+ & \nabla \cdot\left(\rho_{i} \varepsilon_{i} k_{i} U_{i}\right)=\nabla \cdot\left(\varepsilon_{i} \frac{\mu_{t}}{\sigma_{k}} \nabla k_{i}\right) \\
& +\left(\varepsilon_{i} G_{k}-\varepsilon_{i} \rho_{i} \in_{i}\right) \\
\frac{\partial}{\partial t}\left(\varepsilon_{i} \rho_{i} \epsilon_{i}\right)+ & \nabla \cdot\left(\rho_{i} \varepsilon_{i} \in_{i} U_{i}\right)=\nabla \cdot\left(\varepsilon_{i} \frac{\mu_{t}}{\sigma_{k}} \nabla \epsilon_{i}\right) \\
& +\frac{\epsilon_{i}}{k}\left(C_{1 \in} \varepsilon_{i} G_{k}-C_{2 \in} \varepsilon_{i} \rho_{i} \in_{i}\right)
\end{aligned}
$$

The advantage of using $k$ - $\varepsilon$ turbulence model is that its computationally cheap but major weakness is overestimation of turbulence [17].

\subsection{Reaction scheme}

The catalytic cracking of gas oil produces a wide range of products. The present work used 3-lump kinetic scheme proposed by Weekman and Nace [1] and 4-lump kinetic scheme proposed by Gianetto et al. [5] to describe the catalytic cracking reactions. In 3-lump scheme, the gas oil feed is converted to gasoline, light gases plus coke, while in 4-lump scheme gas oil feed is converted to gasoline, light gases and a portion of the gasoline is converted to coke. The catalytic cracking reaction schemes for 3-lump and 4-lump kinetic models are shown in Figures 1 and 2 respectively. Kinetic data for cracking reactions are shown in Table 1 . The reaction kinetics is merged into the mathematical model by solving the species equations of the components in the form of chemical reaction rates [18]. Equations (21)-(23) are used to describe the reaction kinetics of 3-lump kinetic model:

$$
\frac{\mathrm{d} y_{1}}{\mathrm{~d} t}=-k_{1} y_{1}^{2} \phi-k_{3} y_{1}^{2} \phi=-\left(k_{1}+k_{3}\right) y_{1}^{2} \phi=-k_{0} y_{1}^{2} \phi
$$

$$
\begin{aligned}
& \frac{\mathrm{d} y_{2}}{\mathrm{~d} t}=k_{1} y_{1}^{2} \phi-k_{2} y_{2} \phi=\left(k_{1} y_{1}^{2}-k_{2} y_{2}\right) \phi \\
& \frac{\mathrm{d} y_{3}}{\mathrm{~d} t}=\left(k_{3} y_{1}^{2}+k_{2} y_{2}\right) \phi
\end{aligned}
$$

In Equations (21)-(23), $y_{1}$ represents the gas oil mass fraction, $y_{2}$ the gasoline mass fraction and $y_{3}$ the light 


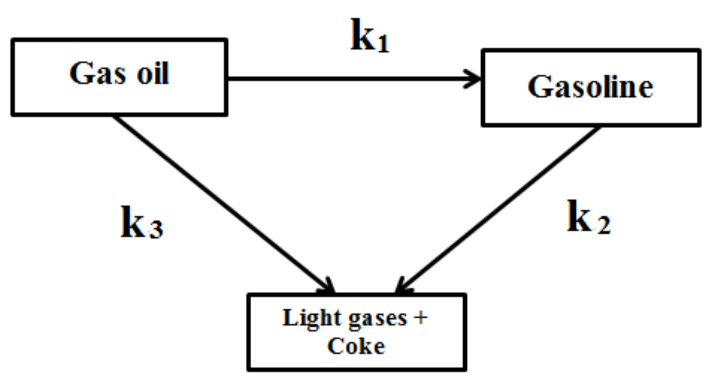

Fig. 1. 3- Lump kinetic model.

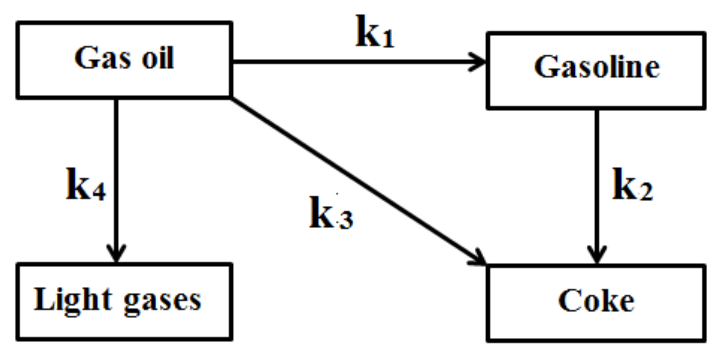

Fig. 2. 4- Lump kinetic model.

gases plus coke mass fraction. Equations (24)-(27) are used to describe the reaction kinetics of 4-lump kinetic model:

$$
\begin{aligned}
\frac{\mathrm{d} y_{1}}{\mathrm{~d} t} & =-k_{1} y_{1}^{2} \phi-k_{3} y_{1}^{2} \phi-k_{4} y_{1}^{2} \phi=-\left(k_{1}+k_{3}+k_{4}\right) y_{1}^{2} \phi \\
& =-k_{0} y_{1}^{2} \phi \\
\frac{\mathrm{d} y_{2}}{\mathrm{~d} t} & =k_{1} y_{1}^{2} \phi-k_{2} y_{2} \phi=\left(k_{1} y_{1}^{2}-k_{2} y_{2}\right) \phi \\
\frac{\mathrm{d} y_{3}}{\mathrm{~d} t} & =\left(k_{3} y_{1}^{2}+k_{2} y_{2}\right) \phi \\
\frac{\mathrm{d} y_{4}}{\mathrm{~d} t} & =k_{4} y_{1}^{2} \phi
\end{aligned}
$$

In Equations (24)-(27), $y_{1}$ represents the gas oil mass fraction, $y_{2}$ the gasoline mass fraction, $y_{3}$ the coke mass fraction and $y_{4}$ the light gases mass fraction.

\subsection{Boundary conditions}

Figure 3 shows the geometry of the riser. GAMBIT pre-processor is used to construct the 2-D geometry. Meshing of the geometry is done by using rectangular grids. The height of the riser is $8.25 \mathrm{~m}$ and diameter is $0.2 \mathrm{~m}$. The flow rate of the gas oil is $10 \mathrm{~kg} . \mathrm{s}^{-1}$ at the bottom of the riser. Other properties of gas oil and solids are mentioned in Table 2.

\subsection{Assumptions}

Following assumptions reported by different researchers are made to simplify the model

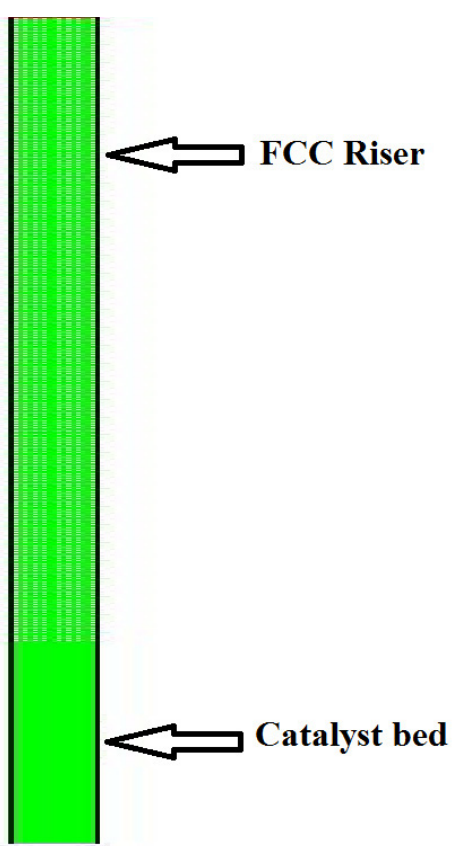

Fig. 3. FCC Riser Mesh.

- At the riser inlet, hydrocarbon feed comes in contact with the hot catalyst coming from the regenerator and instantly vaporizes (taking away latent heat and sensible heat from the hot catalyst). The vapor thus formed moves upwards in thermal equilibrium with the catalyst $[19,20]$.

- There is no loss of heat from the riser and the temperature of the reaction mixture (hydrocarbon vapors and catalyst) falls only because of the endothermicity of the cracking reactions $[20,21]$.

- Ideal gas law is assumed to hold while calculating gas phase velocity variation on account of molar expansion due to cracking and gas phase temperature [21].

- Catalyst particles are assumed to move as clusters to account for the observed high slip velocities [21].

- Heat and mass transfer resistances are assumed as negligible [20,21].

- Both phases are assumed in plug flow condition hence back mixing in both phases is neglected [21].

\section{Simulation set up}

The 2D geometry is discretized using 19915 rectangular cells. Grid size analysis is carried out using three different mesh intervals, i.e. $1 \mathrm{~mm}, 2 \mathrm{~mm}$ and $3 \mathrm{~mm}$. All the simulation results did not show any major difference. FLUENT 6.3 worked a time of $65 \mathrm{~h}$ for $10 \mathrm{~s}$ of real time simulation at a mean time step of 0.001 , number of time steps 100000 , maximum iteration s per time step 40 on a dual core Microsystems with 32 bit processor and 1 GB RAM. The detail simulation procedure is as follow:

(a) Read the mesh.

(b) Specify a transient, 2D model. 
M. Ahsan: Mechanics \& Industry 16, 402 (2015)

Table 1. Kinetic data for cracking reactions [5].

\begin{tabular}{ccc}
\hline Cracking reaction & Pre exponential factor & Activation energy $(\mathrm{J} / \mathrm{kg} \mathrm{mol})$ \\
\hline Gas oil to gasoline & $0.4272 \times 10^{7}$ & 87821.4 \\
Gas oil to light gases & $0.1012 \times 10^{8}$ & 97552.4 \\
Gas oil to coke & $0.5504 \times 10^{5}$ & 87504.1 \\
Gasoline to coke & $0.1337 \times 10^{3}$ & 72988.7 \\
\hline
\end{tabular}

Table 2. Properties of Gas oil \& solids (catalyst).

\begin{tabular}{cccccc}
\hline \multicolumn{2}{c}{ GAS OIL } & \multicolumn{3}{c}{ SOLIDS } \\
\hline Property & Units & Value(s) & Property & Units & Value(s) \\
\hline Density & $\mathrm{kg} \cdot \mathrm{m}^{-3}$ & 9.4 & Density & $\mathrm{kg} \cdot \mathrm{m}^{-3}$ & 3890 \\
Temperature & $\mathrm{K}$ & 620 & Temperature & $\mathrm{K}$ & 980 \\
Cp (Specific Heat) & $\mathrm{j} \cdot \mathrm{kg}^{-1} \mathrm{~K}-1$ & 2430 & Diameter & $\mu \mathrm{m}$ & 60 \\
Thermal Conductivity & $\mathrm{w} \cdot \mathrm{m}^{-1} \cdot \mathrm{K}^{-1}$ & 0.0178 & Cp (Specific Heat) & $\mathrm{j} \cdot \mathrm{kg}^{-1} \cdot \mathrm{K}^{-1}$ & 880 \\
Viscosity & $\mathrm{kg} \cdot \mathrm{m}^{-1} \cdot \mathrm{s}^{-1}$ & $7 \times 10^{-6}$ & Thermal conductivity & $\mathrm{w} \cdot \mathrm{m}^{-1} \cdot \mathrm{K}^{-1}$ & 35 \\
Molecular Weight & $\mathrm{kg} \cdot \mathrm{kg}^{-1} \cdot \mathrm{mol}^{-1}$ & 226.2 & Molecular weight & $\mathrm{kg} \cdot \mathrm{kg}^{-1} \cdot \mathrm{mol}^{-1}$ & 102 \\
Standard State enthalpy & $\mathrm{j} \cdot \mathrm{kg}^{-1} \cdot \mathrm{mol}^{-1}$ & $-3.3 \mathrm{e}+08$ & Standard state enthalpy & $\mathrm{j} \cdot \mathrm{kg}^{-1} \cdot \mathrm{mol}^{-1}$ & -1657.7 \\
\hline
\end{tabular}

(c) Define the multiphase model.

(d) Define the species model.

(e) Define the materials and balanced chemical reactions.

(f) Specify the species for the gaseous phase and the bed phase.

(g) Define the granular secondary phase

(h) Specify the drag law to be used for computing the interphase momentum transfer.

(i) Set the gravitational acceleration.

(j) Define the boundary conditions.

(k) Adapt the regions to be patched.

(l) Set the solution parameters.

(m) Initialize the solution.

(n) Set the time stepping parameters.

(o) Post-processing.

There are no universal metrics for judging convergence. Residual definitions that are useful for one class of problem are sometimes misleading for other classes of problems. Therefore it is a good idea to judge convergence not only by examining residual levels, but also by monitoring relevant integrated quantities such as drag or heat transfer coefficient. For most problems, the default convergence criterion in FLUENT is sufficient. This criterion requires that the scaled residuals decrease to $10^{-3}$ for all equations except the energy and radiation equations, for which the criterion is $10^{-6}$. In this simulation the residuals decrease to $10^{-12}[22]$.

\section{Results and discussion}

This study illustrates simulation results for computational parameters. In this paper model predicts the temperature profile in the riser, phase temperature profile and mass fraction profile of a gasoil, gasoline, light gases and coke. Although the model is very simplified in this study, it reasonably predicts the trends of variations of gas and catalyst temperatures in the FCC riser as shown in Figure 4. At the moment of initial contact between the hot regenerated catalyst and the vaporized feedstock (directly as the gas phase), the gas phase heated sharply to a mixer temperature in the inlet region of the riser reactor. As expected the temperature decreases significantly from the bottom to top of the riser. The variations of the phase temperatures are qualitatively consistent with the literature [23-26]. Figure 5 shows the temperature in the riser height. We can observe that the temperature of the riser is descending as the nature of the reaction is endothermic. Due to the high temperature at bottom of the riser the gasoline yield increased, but because of coke deposition on catalyst the gasoline yield decreased after attaining a maximum value.

Figure 6 predicts gasoline profile in the riser height. The model shows that the conversion of gas oil is mostly occurring in the first $4 \mathrm{~m}$ of the riser, which is alike to the profiles, reported by other researchers $[18,24,25]$. The profile shows that the mass fraction of gas oil is descending gradually. In the riser height the yield of gasoline increased significantly. There are several reasons for this; first riser has a high catalyst activity at the bottom. Moreover, the concentration of the gas oil decreases at the bottom due to molar expansion and reaction, thus the reaction rate of gas oil to gasoline is greatest at the bottom of riser. Table 3 shows the comparison of plant data with results predicted in this model. We can observe the good agreement between plant data and model results.

After the detail modeling of FCC riser using FVM solver, the major following differences in results of both kinetic models are observed: (a) there is no significant difference of phase temperature in both lump models along the riser height, (b) at exit the temperature of a riser in 4-lump model is higher than 3-limp model, (c) in 4-lump model prediction of gasoline yield is better than 3-lump kinetic model, (d) the gasoline yield calculated by 4-lump 
Table 3. Comparison of calculated model results with other models and plant data.

\begin{tabular}{|c|c|c|c|c|c|c|c|c|}
\hline & & \multirow{2}{*}{ This Model } & \multicolumn{2}{|c|}{ Gupta [27] } & \multicolumn{2}{|c|}{ Lan [28] } & \multicolumn{2}{|c|}{ Ali $[20]$} \\
\hline & & & Model & Error \% & Model & Error \% & Plant & Error \% \\
\hline \multirow{4}{*}{$\begin{array}{c}\text { 3- Lump kinetic } \\
\text { model }\end{array}$} & Gasoline Yield (wt \%) & 39 & 43 & 9.30 & 40 & 2.5 & 44 & 11.36 \\
\hline & Light Gases + Coke (wt \%) & 30 & 24 & 25 & 25 & 20 & 26 & 15.38 \\
\hline & Unconverted gas oil (wt \%) & 28 & 30 & 6.67 & 33 & 15.15 & 28 & 0 \\
\hline & Riser temperature & 760 & 775 & 1.94 & 773 & 1.68 & 795 & 4.40 \\
\hline \multirow{5}{*}{$\begin{array}{l}\text { 4- Lump kinetic } \\
\text { model }\end{array}$} & Gasoline Yield (wt \%) & 41 & 43 & 4.65 & 40 & 2.50 & 44 & 6.82 \\
\hline & Light Gases (wt \%) & 26 & 20 & 30.00 & 21 & 23.81 & 20 & 30.00 \\
\hline & Coke (wt \%) & 05 & 04 & 25.00 & 04 & 25.00 & 06 & 16.67 \\
\hline & Unconverted gas oil (wt \%) & 26 & 30 & 13.33 & 33 & 21.21 & 28 & 7.14 \\
\hline & Riser temperature & 765 & 775 & 1.29 & 773 & 1.03 & 795 & 3.77 \\
\hline
\end{tabular}

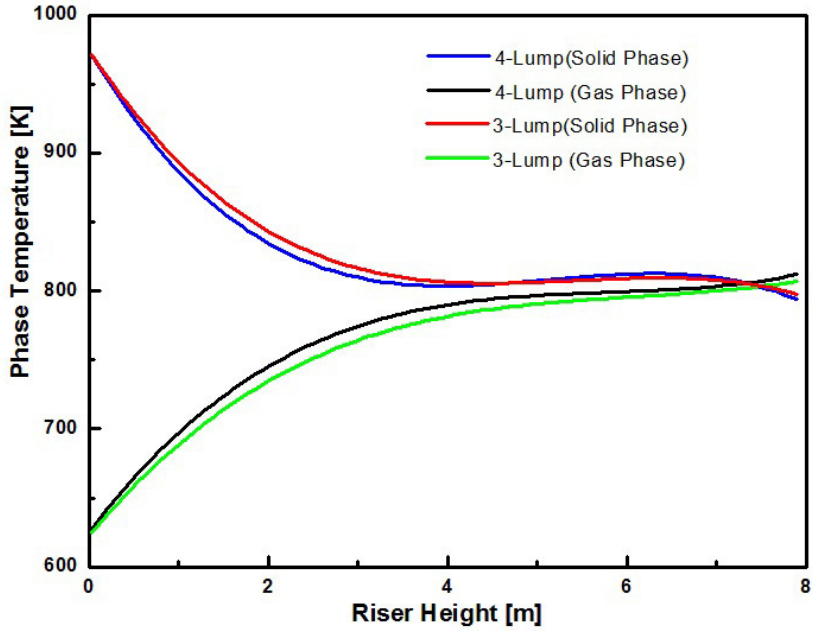

Fig. 4. Phase temperature (gas oil and catalyst).

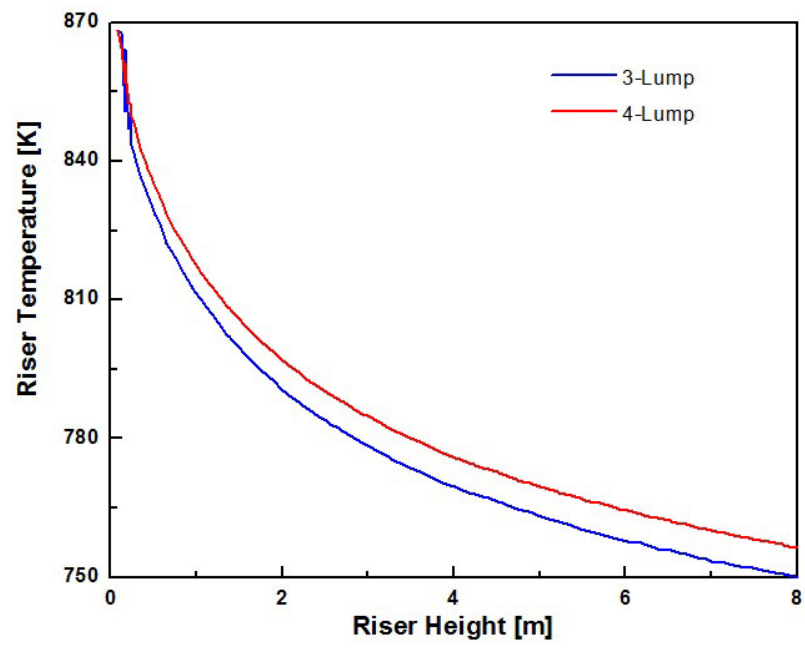

Fig. 5. Temperature in a FCC riser.

kinetic model has small percentage error when compared with other researcher models and plant data available in literature.

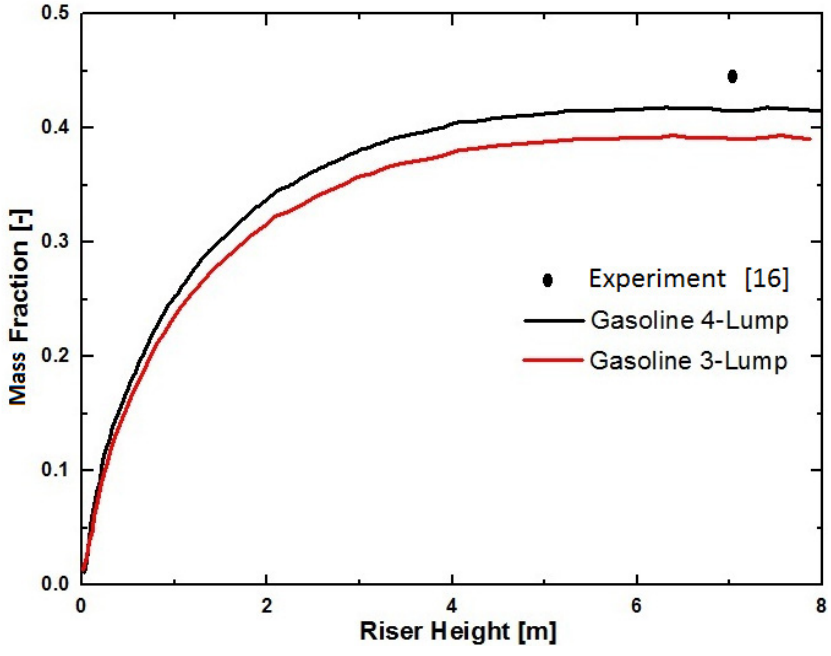

Fig. 6. Gasoline yield in the riser height.

\section{Conclusions}

A two dimensional multiphase flow reaction model for FCC riser has been developed by using commercial FVM solver FLUENT 6.3 with the 3-lump and 4 lump reaction kinetics models of Weekman and Gianetto et al. respectively. Mass fraction profiles, phase temperature profiles and riser temperature profiles are predicted by using multiphase model. The simulation predicts that the inlet zone of the FCC riser is the most complex segment. Mostly the reaction occurs in first 1-3 meters of the FCC riser length. A novel transient case for 3-lump and 4-lump kinetic models has been considered for the various properties of gas oil and catalyst. A complex FCC riser is investigated numerically by using CFD approach. The model consisting of large number of equations of FVM, is solved efficiently. So, CFD mode capable of handling different constraints, could be implemented for calculating the accurate results of FCC riser. In this research work, CFD simulation results for both gas phase and solid phase have been examined. It is observed in comparison of both kinetic models, that the CFD prediction of the gasoline yield and riser temperature in 4-lump kinetic model gives the lowest error percentage from the plant data. This is because of the consideration of separate lump of light gases in CFD simulation for 4-lump kinetic model. A good agreement 
is observed between the plant data and model results. The proposed model is applicable for all simulation processes of FCC riser. More accurate results can be predicted by implementing the model to a 3D geometry with fewer assumptions and coupling FCC riser with regenerator model.

\section{References}

[1] V.W. Weekman, D.M. Nace, Kinetics of catalytic cracking selectivity in fixed, moving, and fluid bed reactors, AIChE Journal 16 (1970) 397-404

[2] J. Wei, C.D. Prater, A new approach to first-order chemical reaction systems, AIChE Journal 9 (1963) 77-81

[3] L.S. Lee, Y.W. Chen, T.N. Huang, W.Y. Pan, Four-lump kinetic model for fluid catalytic cracking process, Can. J. Chem. Eng. 67 (1989) 615-619

[4] N.C. Dave, G.J. Duffy, P. Udaja, A four-lump kinetic model for the cracking/coking of recycled heavy oil, Fuel. 72 (1993) 1331-1334

[5] A. Gianetto, H.I. Farag, A.P. Blasetti, H.I. de Lasa, Fluid catalytic cracking catalyst for reformulated gasolines, Kinetic modeling, Ind. Eng. Chem. Res. 33 (1994) 3053-3062

[6] G. Niccum, S. White, Troubleshooting refinery equipment with multiphase CFD modelling, Petroleum Technology Quarterly 19 (2014) 133-137

[7] L. Jiang, X. Fang-Zhi, L. Zheng-Hong, A CFD modeling of the gas-solid two-phase flow in an FCC riser under the electrostatic conditions, Asia-Pacific J. Chem. Eng. 9 (2014) 645-655

[8] J. Chang, W. Cai, K. Zhang, F. Meng, L. Wang, Y. Yang, Computational investigation of the hydrodynamics, heat transfer and kinetic reaction in an FCC gasoline riser, Chem. Eng. Sci. 111 (2014) 170-179

[9] Y.M. Ferng, K.-Y. Lin, Investigating effects of BCC and FCC arrangements on flow and heat transfer characteristics in pebbles through CFD methodology, Nucl. Eng. Design 258 (2013) 66-75

[10] M. Syamlal, T. O'Brien, Computer simulation of bubbles in a fluidized bed, AIChE Symp. Ser. 270 (1989) 22-31

[11] R. Di Felicea, M. Rotondia, Fluid-particle Drag Force in Binary-solid Suspensions, Int. J. Chem. Reactor Eng. 10 (2012) 1542-6580

[12] J. Garside, M.R. Al-Dibouni, Velocity-voidage relationships for fluidization and sedimentation in solid-liquid systems, Ind. Eng. Chem. Process Design Dev. 16 (1977) 206-214

[13] S. Chapman, T.G. Cowling, The mathematical theory of non-uniform gases: an account of the kinetic theory of viscosity, thermal conduction and diffusion in gases, Cambridge University Press, 1991
[14] S. Ogawa, A. Umemura, N. Oshima, On the equations of fully fluidized granular materials, Zeitschrift für Angewandte Mathematik und Physik (ZAMP) 31 (1980) 483-493

[15] N. Chepurniy, Kinetic theories for granular flow: inelastic particles in Couette flow and slightly inelastic particles in a general flowfield, J. Fluid Mech. 140 (1984) 223-222.256

[16] D. Gidaspow, R. Bezburuah, J. Ding, Hydrodynamics of circulating fluidized beds: kinetic theory approach. Illinois Inst. of Tech., Chicago, IL (United States). Dept. Chem. Eng. (1991)

[17] M. Ahsan, Computational fluid dynamics (CFD) prediction of mass fraction profiles of gas oil and gasoline in fluid catalytic cracking (FCC) riser, Ain Shams Eng. J. 3 (2012) 403-409

[18] N. Novia, M.S Ray, V. Pareek, Three-dimensional hydrodynamics and reaction kinetics analysis in FCC riser reactors, Chemical Product and Process Modeling 2 (2007) $1-17$

[19] A. Gupta, D. Subba Rao, Model for the performance of a fluid catalytic cracking (FCC) riser reactor: effect of feed atomization, Chem. Eng. Sci. 56 (2001) 4489-4503

[20] H. Ali, S. Rohani, J. Corriou, Modelling and control of a riser type fluid catalytic cracking (FCC) unit, Chem. Eng. Res. Design 75 (1997) 401-412

[21] P.K. Dasila, I. Choudhury, D. Saraf, S. Chopra, A. Dalai, Parametric Sensitivity Studies in a Commercial FCC Unit, Adv. Chem. Eng. 2 (2012) 136-149

[22] Fluent-Inc, Fluent 6.3. User's Guide, Fluent Inc, 2006

[23] A. Mahecha-Botero, J.R. Grace, S. Elnashaie, C.J. Lim, Advances in modeling of fluidized-bed catalytic reactors: a comprehensive review, Chem. Eng. Commun. 196 (2009) 1375-1405

[24] A.K. Das, E. Baudrez, G.B. Marin, G.J. Heynderickx, Three-dimensional simulation of a fluid catalytic cracking riser reactor, Ind. Eng. Chem. Res. 42 (2003) 2602-2617

[25] V. Pareek, A. Adesina, A. Srivastava, R. Sharma, Sensitivity analysis of rate constants of Weekman's riser kinetics and evaluation of heat of cracking using CATCRAK, J. Mol. Catal. A: Chem. 181 (2002) 263-274

[26] S. Benyahia, A. Gonzalez Ortiz, P. Paredes, J. Ignacio, Numerical analysis of a reacting gas/solid flow in the riser section of an industrial fluid catalytic cracking unit, Int. J. Chem. Reactor Eng. 1 (2003) A41

[27] R.K. Gupta, V. Kumar, V. Srivastava, A new generic approach for the modeling of fluid catalytic cracking (FCC) riser reactor, Chem. Eng. Sci. 62 (2007) 4510-4528

[28] X. Lan, C. Xu, G. Wang, L. Wu, J. Gao, CFD modeling of gas-solid flow and cracking reaction in two-stage riser FCC reactors, Chem. Eng. Sci. 64 (2009) 3847-3858 